\title{
Treatment of Industrial Wastewater by using Amberlite XAD-1180 in A Fluidized-Bed Reactor
}

\author{
K.Harsha Vardhan, K.Harsh Vardhan, B.Sarada
}

\begin{abstract}
The main objective of the work is to reduce COD levels of industrial effluents Using Amberlite XAD-1180 in a fluidization reactor. The experiment runs at the flowrates in the range 2 to $8 \mathrm{LPM}$. The parameters like flow-rate, time \& dosage of $X A D$ have been studied and their effect of $C O D$ reduction is analysed, for this experiment COD analysis was done for industrial wastewater which is taken from near by industry. The $C O D$ reduction increases with increasing flow rate and adsorbent dosage. The maximum percentage $C O D$ reduction is found to be $91.56 \%$. Maximum adsorption occurs at the flow rate of 8 LPM and with $20 \mathrm{gm}$ of XAD adsorbent.
\end{abstract}

Keywords - adsorption, Amberlite XAD - 1180, fluidization bed unit.

\section{INTRODUCTION}

Pollution is one of natural water resources 'biggest issues. Excessive dumping in water bodies of industrial waste makes the water harmful for human requirements. The main problem is water pollution, triggered primarily by the release of heavy metals, dairy waste and fertilizer sector and other chemicals substance. To overcome this problem, Fluidization is a technique used across the world for treatment of industrial effluents. Due to their high efficiency in removing COD, fluidized reactors have attracted considerable importance in wastewater treatment (Jeris et al., 1977; Yoon Chan Choi, Dong Seog Kim, Tae Joo Park, 3Kyung Kee Park- and Seung Koo Song, 1995). High contact effectiveness between the solid and liquid phases and used effectively for both aerobic and anaerobic processes is one of its benefits. (Walker, D.F., andE.P.Austin.1981; Sokoł. W and M. R. Halfani. 1999), for example aerobic/anaerobic starch wastewater treatment (M. Rajasimman, C. Karthikeyan, 2007), Domestic wastewater treatment(Da-wen Gao, Qi Hu, Chen Yao, Nan-Qi Ren,2014), anaerobic real textile wastewater treatment(S.Sen, G.N Demirer, 2003) and anaerobic/aerobic treatment of complex industrial wastewater(Prof. Dr. Ir. Sef. Heijnen, Arnold Mulder, Rene Weltevrede, Pam H. Hols, HansL. J. M . Van Leeuwen , 1990).

The Fludized bed was developed by Fritz Winkler in Germany in the 1920s had an internal draft tube causing the liquid to circulate in the bioreactor due to airlift principle. Right now, some modified fluidized-bed reactors are using

Revised Manuscript Received on July 18, 2019.

K.Harsha Vardhan, Department of Biotechnology, GITAM (Deemed to be University), Visakhapatnam, Andhra Pradesh. (E-mail: harshakandi567@gmail.com)

K.Harsh Vardhan, Department of Biotechnology, GITAM (Deemed to be University), Visakhapatnam, Andhra Pradesh

Dr B.Sarada, Department of Biotechnology, GITAM (Deemed to be University), Visakhapatnam, Andhra Pradesh for wastewater treatment like IFBR...etc. It has a lot of benefits over fixed bed reactors(Sokol, W 2001).It is particularly suitable for solids processing where good mixing and close temperature control is required. Among its advantages, the main advantage is that the particles are well mixed leading to low temperature gradients, they are suitable for both small and large scale operations. Theimplementation of fluidization has risen significantly in the sector of chemical, biochemical engineering and wastewater treatment and well recognised in chemical, petrochemical, metallurgical, mineral and biochemical operations (MM Bello, AAA Raman, Bello, M Purushothaman, 2017). In the present study we used fluidization technique to reduce COD content of nearby industrial effluent

\section{EXPERIMENTAL \& RESULTS}

\section{Material}

$\mathrm{XAD}$ is used as an adsorbent in this experiment to reduce COD levels The adsorbent is acquired commercially, which can be used readily in experiments. Potassium Dichromate solution was prepared by dissolving $12.25 \mathrm{~g}$ of $\mathrm{K} 2 \mathrm{Cr} 2 \mathrm{O} 7 \mathrm{in}$ $1000 \mathrm{ml}$ of Ferrous Ammonium Sulphate and dissolve $98 \mathrm{~g}$ of FAS in distilled water and then adding $20 \mathrm{ml}$ of Concentrated Sulphuric acid and dilute the solution to $1000 \mathrm{ml}$. These stock solutions are used for COD analysis.

\section{Methodology}

The Figure shows a scheme diagram of the test set-up. The experiment was conducted in a fluidized bed (FDR) labscale plant with diameter of $100 \mathrm{~mm}$, height $1240 \mathrm{~mm}$ and thickness $3 \mathrm{~mm}$ which is made up of perspex fabric. A weir mesh was placed at the bottom to support the adsorbent and at the top to prevent any escape of adsorbent from the column The industrial wastewater is sent to the fluidized bed reactor through liquid distributer. The monometer is connected to the fluidized bed from the bottom and top connection. For every run the pressure drop is obtained. The pressure taps are evenly spaced at $100 \mathrm{~mm}$ intervals on the top and bottom of the column and connected to manometers. The column is packed from the bottom of the column with solid particals of a specific size and density for the necessary bed height. 


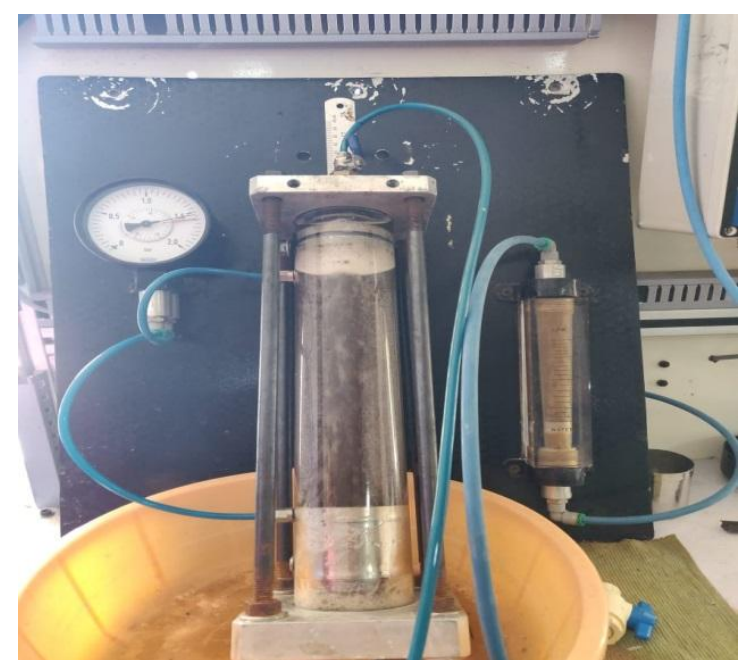

Figure1. Fluidized bed reacter

In the present case Amberlite XAD-1180 was taken. The Effluents from nearby industy is used and supplied from the bottom at different flowrates of 2,4,6 \& 8 LPM. The sample was drawn at periodic intervals of 60 minutes, up to 6 measurements. COD was determined by COD analysis method. The reduction percent of COD was calculated after treating with XAD

\%removal $=\mathrm{Co}-\mathrm{Ci} * 100 / \mathrm{Co}$

where $\mathrm{Co}=$ initial concentration of $\mathrm{COD}$

$\mathrm{Ci}=$ final concentration of COD.

\section{RESULT AND DISCUSSIONS}

\section{Effect of flowrate on COD removal :}

To know the flow-rate effect on removal of COD, the fludization experiment was run at 2 to 8 LPM with adsorbent 20gm of XAD. We observe the increase in removal of COD with increase in flow-rates. The working solution is same for all experiments. It is prepared by adding 2.5 lit of industrial effluents to 2.5 lit water. The percentage removal of COD was show in fig 2.

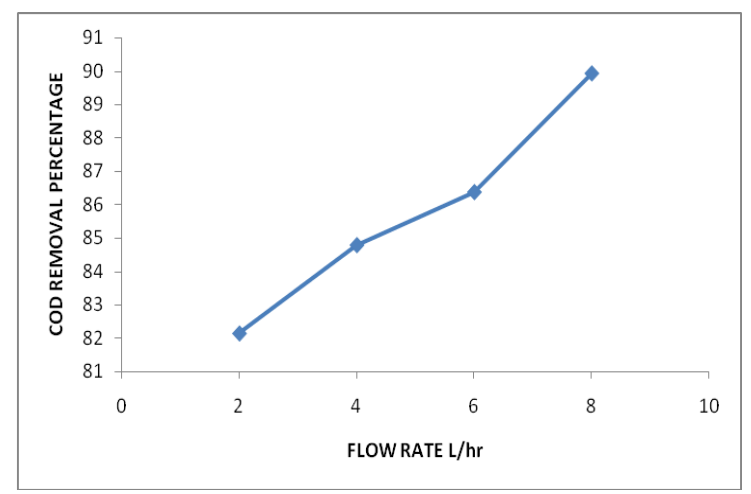

Figure2. flow-rate vs cod removal

Effect of time on COD reduction:

To know the effect of time on COD removal, the fluidization experiment was run for $6 \mathrm{hrs}$ with adsorrbent $20 \mathrm{gm}$ of XAD. We observed that removal percentage is increased with change in time. The COD reduction proportion was shown in fig 3 .
After the adsorption the removal concentration of the

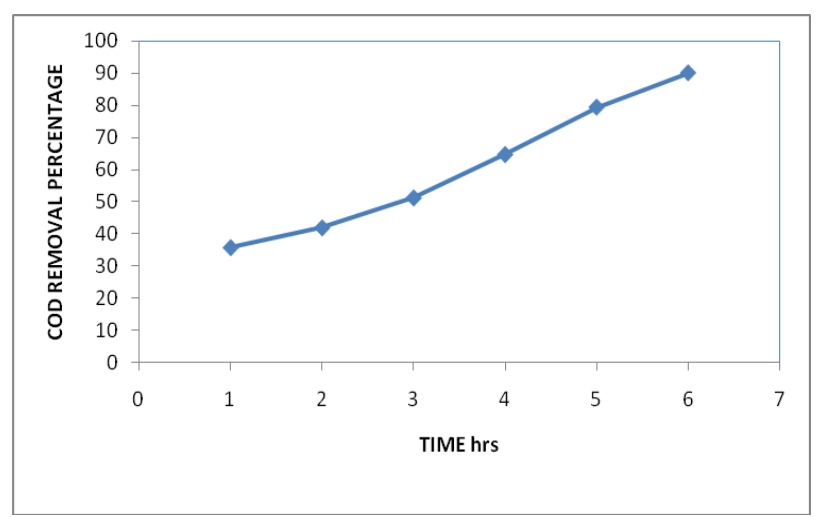

Figure 3. Time vs COD removal

Effect of XAD dosage on COD removal:

To know the effect of dosage on COD removal, the fluidization experiment was run by different amounts of XAD. We got maximum efficiency by using $20 \mathrm{gm}$ of XAD with 8 LPM flow-rate. The percentage removal of COD was show in fig4

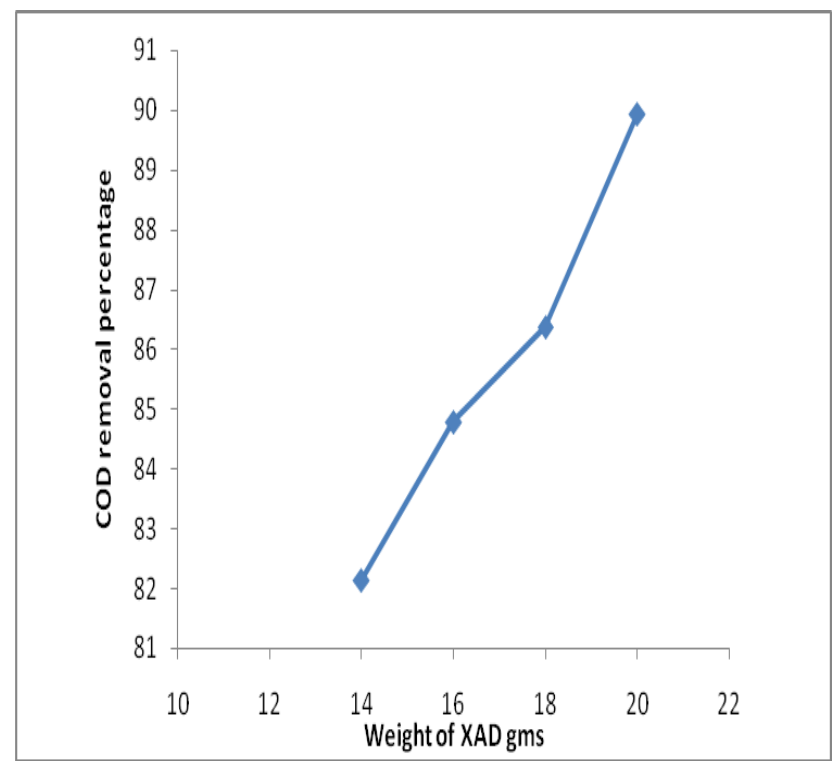

Figure 4. Dosage of XAD vs COD removal

\section{CONCLUSION}

How to make the water fit for human consumption by removing the pollutants is a major chellange that faces the science of biotechnology. Waste-water plants shall do proper COD analysis which is the critical step in cleaning pollutant water. The cost benifit ratio and harmful end products are the two major ills effecting many water treatment procesures currently available. The present study aims at reducing the cost and increasing the efficency in removing the harmful materials from industrial pollutad waste-water by using fluidization technique. XAD is the one of the best adsorbent for removal of COD from industrial wastewater Treatment in fluidized-bed reactor. The performance is satisfactory with approximately $91.5 \%$ COD levels being reduced. Maximum reduction of COD levels in effluents are seen at $20 \mathrm{gm}$ of XAD at flow-rate of $8 \mathrm{lpm}$.

Published By: 


\section{REFERENCES:}

1. Jeris et al., 1977; waste treatment process; us patent 4,009,098.

2. Yoon Chan Choi, Dong Seog Kim, Tae Joo Park, 3Kyung Kee Park and Seung Koo Song, 1995; Wastewater treatment in a pilot scale inverse fluidized-bed biofilm reactor; Biotechnology techniques, volume 9, issue 1, page 35-40.

3. DF.Walker, and EP.Austin.1981. Theuseofplastic,porous biomass supports in a pseudo-fluidised bed for effluent treatment, 272-284. 10th United States-Japan Conference on Sewage Treatment and North Atlantic.

4. W.Sokot, and MR. Halfani. 1999. Hydrodynamics of a gasliquidsolid fluidised bed bioreactor with a low density biomass support. Biochemical Engineering Journal 3:185-192

5. M.Rajasimman, C.Karthikeyan, 2007; Aerobic digestion of starch wastewater in a fluidized bed bioreactor with low density biomass support; volume 143, issues 1-2, pages 82-86.

6. Da-wen Gao, Qi Hu, Chen Yao, Nan-Qi Ren, 2014; Treatment of domestic wastewater by an integrated anaerobic fluidizebed membrane bioreactor under moderate to low temperature conditions, Bioresource technology, volume 159, pages 193 198.

7. S.Sen, GN.Demirer, 2003; anaerobic treatment of real textile wastewater with a fluidized-bed reactor, Water research, volume 37, issue 8, pages 1868-1878.

8. Prof. Dr. Ir. Sef. Heijnen, Arnold Mulder, Rene Weltevrede, Pam H. Hols, HansL. J. M . Van Leeuwen, 1990; Large scale aerobic/anaerobic treatment of complex industrial wastewater using immobilized biomass in fluidized-bed and air lift suspension reacter. Chemical engineering technology, volume 13 , issue 1 , pages 202-208.

9. W.Sokol, (2001). Operating Parameters for a gas-liquid-solid fluidized bed bioreactor with a low-density biomass support. Biochemical Engineering Journal 8:203-212

10. MM Bello, AAA Raman, Bello, M.Purushothaman, 2017. Applications of fluidized bed reactors in wastewater treatment - A review of the major design and operational parameters. Journal of Cleaner Production, Volume 141, pages 1492 1514. 